DOI: https://doi.org/10.24127/ajpm.v10i2.3522

\title{
KEMAMPUAN MAHASISWA DALAM MENYELESAIKAN SOAL MATEMATIKA BERTIPE HIGH ORDER THINKING SKILLS (HOTS)
}

\author{
Fida Rahmantika Hadi ${ }^{*}$ \\ ${ }^{1 *}$ Universitas PGRI Madiun, Madiun, Indonesia \\ *Corresponding author \\ E-mail: fida@unipma.ac.id ${ }^{1 *}$
}

Received 01 February 2021; Received in revised form 12 June 2021; Accepted 06 July 2021

\begin{abstract}
Abstrak
Penelitian ini bertujuan untuk mendeskripsikan kemampuan mahasiswa PGSD dalam menyelesaikan soal matematika bertipe high order thinking skills (HOTS). Penelitian ini merupakan penelitian kualitatif dekriptif. Subjek adalah 28 mahasiswa pada mata kuliah Geometri semester 3 Prodi PGSD Universitas PGRI Madiun. Analisis data dilakukan dengan menganalisis data hasil tes dan wawancara. Hasil tes mahasiswa dikelompokkan menjadi kemampuan tinggi (nilai tes lebih dari 85), sedang (nilai tes antara 65-85, rendah (nilai tes kurang dari 65). Selanjutnya untuk wawancara dari masing-masing kelompok dipilih satu mahasiswa secara purposive. Hasil penelitian ini yaitu terdapat 5 mahasiswa kemampuan tinggi, 10 sedang dan 13 rendah. Masing-masing kelompok diambil satu subjek untuk dianalisis hasil tes dan wawancara. Subjek kemampuan tinggi mampu memenuhi ketiga indikator, subjek kemampuan sedang hanya memenuhi kedua indikator sedangkan subjek kemampuan rendah tidak memenuhi ketiga indikator. Jadi dapat disimpulkan bahwa kemampuan mahasiswa PGSD dalam menyelesaikan soal matematika bertipe HOTS masih cukup rendah. Mahasiswa dikatakan mampu menyelesaikan soal HOTS jika memenuhi ketiga indikator. Indikator yang digunakan dalam menyelesaikan soal matematika bertipe HOTS yaitu menganalisis, mengevaluasi dan memberikan solusi.
\end{abstract}

Kata kunci: HOTS; kemampuan mahasiswa PGSD; soal matematika.

\begin{abstract}
This study aims to describe the ability of PGSD students in solving HOTS-Type Mathematics Problems. This research is a descriptive qualitative research. The subjects is 28 students in the 3rd semester Geometry course, PGSD Study Program, PGRI Madiun University. Data analysis was carried out by analyzing test and interview data. The results of student test scores were grouped into three consisting of high ability (test score more than 85), moderate ability (test score between 65-85, low ability (test score less than 65). Furthermore, for interviews from each group, one student was selected. purposively. The results of this study are 5 students with high ability, 10 students with moderate ability and 13 students with low ability. Each group is taken one subject to analyze test and interview results. Subjects with high ability are able to meet all three indicators, subjects with moderate ability only meet the two indicators while the subject of low ability does not meet the three indicators. So it can be concluded that the ability of PGSD students in solving HOTS type math problems is still quite low. Students are said to be able to solve HOTS questions if they meet all three indicators. The indicators used in solving HOTS type math problems a in analyzing, evaluating and providing solutions.
\end{abstract}

Keywords: HOTS; mathematic problems; PGSD student ability.

This is an open access article under the Creative Commons Attribution 4.0 International License

\section{PENDAHULUAN}

Pendidikan yang berkembang pesat menjadi faktor utama dalam pembelajaran masa depan. Pembelajaran abad 21 diperlukan generasi yang kreatif, inovatif, serta kompetitif. Mahasiswa dituntut untuk dinamis dalam menghadapi segala perubahan agar dapat berkompetisi di Abad 21 (Afrianto, 2018). Mahasiswa 
tidak hanya dibekali penguasaan konsep tetapi juga bekal keterampilan (Maimunah et al., 2020). Berbagai keterampilan yang harus dikuasai diantaranya berpikir tingkat tinggi atau HOTS (Andriyani \& Yenni, 2019). HOTS level berpikir tertinggi memungkinkan bagi mahasiswa untuk mengolah informasi yang begitu banyak secara efektif dan efisien (Tan \& Halili, 2015). HOTS adalah level tertinggi dalam Taksonomi Bloom yaitu menganalisis, mengevaluasi dan mencipta (Narayanan \& Adithan, 2015)

Pembelajaran HOTS didasari oleh beberapa komponen yaitu analisis, evaluasi, penalaran logis, pemikiran kritis, pemecahan masalah dan pemikiran kreatif (Hasyim \& Andreina, 2019). Kemampuan HOTS dapat dilatih dengan memberikan pertanyaan tipe penalaran ketika proses pembelajaran (Tambunan \& Naibaho, 2019). HOTS ditandai dengan kemampuan mengelola informasi lebih dari sekedar recall atau mengingat (Manik et al., 2020).

Yaniawati (2013) menjelaskan dalam penelitian bahwa HOTS memegang peran penting dalam meningkatkan efektivitas proses pembelajaran. HOTS dapat dikatakan mampu mengantarkan mahasiswa pada kesuksesan dalam pembelajaran (Tanujaya, 2016). Oleh karena itu, dosen menjadi fasilitator yang memberikan dukungan, informasi sumber dan mengarahkan mahasiswa untuk mendapatkan pengalaman belajar yang nyata sebagai upaya mengembangkan HOTS (Rosidin et al., 2019). Penguasaan mahasiswa dalam konten matematika perlu dimiliki agar mereka dalam mengolah informasi dapat secara logis dan analitis.

Penguasaan konten matematika dan HOTS menjadi salah satu faktor penentu dalam dunia pendidikan. Guru
SD mendidik generasi selanjutnya untuk mencapai tujuan pembelajaran dengan baik. HOTS mahasiswa PGSD perlu diketahui terkait bidang matematika. Beberapa penelitian sebelumnya telah banyak mengungkapkan strategi untuk meningkatkan HOTS mahasiswa calon guru (Zulfiani et al., 2020). Hasil penelitian tersebut menjelaskan bahwa HOTS mahasiswa PGSD berada di kategori sedang dan perlu untuk ditingkatkan lagi. Penelitian lain juga menyebutkan sebagai mahasiswa calon guru sekolah dasar belum mempunyai kemampuan merancang dan melaksanakan pembelajaran HOTS di SD (Dosinaeng et al., 2019). Padahal calon guru SD perlu menguasai konten dan kemampuan HOTS sebagai upaya meningkatkan rasa percaya diri dan mengefektifkan pembelajaran yang akan mereka lakukan kelak (Singh et al., 2018).

HOTS adalah keterampilan yang guru inginkan agar siswa mampu memiliki dan mengembangkan kemampuan setelah mengikuti pembelajaran matematika di kelas (Ahmad et al., 2018). Penguasaan terhadap pembelajaran HOTS merupakan faktor penting yang perlu dikuasai seperti yang dijelaskan dalam penelitian (F. R. Hadi, 2021). Peningkatan kemampuan HOTS dilihat dari hasil yang ditunjukkan PISA. Program ini dirancang dalam periode tiga tahun dalam penilaian dunia. Hasil PISA menunjukkan bahwa Indonesia masih termasuk pada skor di bawah rata-rata. Amalia et al., (2021) menyatakan dalam penelitiannya bahwa jika dilihat hasil studi PISA menjelaskan kemampuan siswa dalam matematika masih kurang.

Jadi dalam hal ini diharapkan mahasiswa mempunyai kelebihan dalam kemampuan mengerjakan soal HOTS. 
DOI: https://doi.org/10.24127/ajpm.v10i2.3522

\begin{abstract}
Mahasiswa yang mempunyai kemampuan HOTS harus dapat mengingat rumus selain itu juga harus mampu memahami soal dan mengaplikasikan, serta mampu menganalisis masalah matematika Tidak hanya itu mahasiswa juga mampu mengevaluasi hasil kerja, dan menciptakan kreasi baru. (Winarso, 2014). Tidak hanya siswa saja yang harus memiliki keterampilan berpikir HOTS, namun mahasiswa calon guru SD juga demikian agar nantinya ketika mengajar mampu membimbing siswanya dalam mengembangkan HOTS (W. Hadi \& Faradillah, 2020). Aspek dan indikator yang digunakan dalam soal HOTS meliputi menganalisis, mengevaluasi, dan memberikan solusi yang tepat. Penelitian ini bertujuan untuk mendiskripsikan kemampuan yang dimiliki mahasiswa PGSD dalam soal matematika bertipe HOTS.
\end{abstract}

\section{METODE PENELITIAN}

Penelitian ini merupakan penelitian kualitatif deskriptif. Penelitian bertempat di Universitas PGRI Madiun. Subjek adalah 28 mahasiswa di semester 3 PGSD yang menempuh mata kuliah Geometri. Instrumen data adalah tes dan wawancara. Tes yang digunakan soal uraian untuk mengukur kemampuan mahasiswa ketika mengerjakan soal matematika bertipe HOTS. Wawancara dilakukan sebagai penguatan untuk mengkonfirmasi hasil tes tertulis yang kurang jelas. Pertama mahasiswa mengerjakan soal tes terlebih dahulu kemudian dilanjutkan dengan menganalisis data hasil dari tes untuk mengelompokkan mahasiswa dengan kemampuan tinggi, sedang dan rendah. Setelah mengelompokkan kedalam tiga kategori kemudian dipilih masing- masing satu mahasiswa secara purposive atau acak dan menganalisis hasil tes dengan wawancara secara kualitatif. Penelitian pada saat pandemi Covid-19 dilakukan dengan online yaitu menggunakan teknologi seperti zoom dan whatsapp group.

Analisis data sebagai berikut: (1) Mereduksi hasil data, (2) Menyajikan data tes dan wawancara mahasiswa, (3) Memberikan kesimpulan penelitian dan (4) Triangulasi dengan memanfaatkan penggunaan triangulasi teknik. Triangulasi teknik untuk mendapatkan data dari subjek dengan metode yang berbeda yaitu dengan perbandingan hasil dari tes dan wawancara.

\section{HASIL DAN PEMBAHASAN}

Hasil tes yang diperoleh oleh 28 mahasiswa, kemudian dikelompokkan menjadi tiga bagian dilihat dari skor nilai tes yang didapat. Pengelompokan mahasiswa berdasarkan hasil tes disajikan dalam Tabel 1.

Tabel 1. Pengelompokan mahasiswa berdasarkan hasil tes

\begin{tabular}{ccc}
\hline $\begin{array}{c}\text { Tingkat } \\
\text { Kemampuan }\end{array}$ & Skor & $\begin{array}{c}\text { Jumlah } \\
\text { Mahasiswa }\end{array}$ \\
\hline Tinggi & $>85$ & 5 \\
\hline Sedang & $65-85$ & 10 \\
\hline Rendah & $<65$ & 13 \\
\hline
\end{tabular}

Tabel 1 merupakan tabel pengelompokan hasil skor tes, ternyata masih banyak mahasiswa yang berada pada kelompok kemampuan sedang dan rendah. Selanjutnya akan dipilih subjek A (SA), subjek B (SB), dan subjek C (SC). Hasil tes dari ketiga subjek dianalisis dan dilanjutkan dengan wawancara. Hasil jawaban SA terlihat pada lembar jawab pada Gambar 1. 


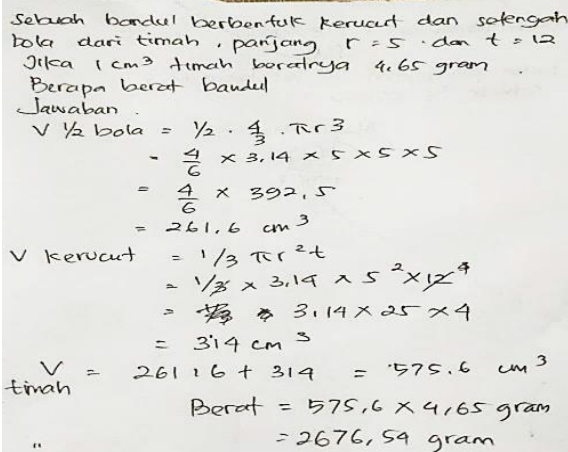

Gambar 1. Jawaban soal pertanyaan dari SA

Dilihat dari hasil jawaban pada gambar 1, SA mampu menjawab dengan benar. Mulai dari menuliskan yang diketahui di soal sampai proses perhitungan volume bandul. Ini berarti SA mampu menganalisis soal, mengevaluasi dan memberikan solusi yang tepat. Jadi hasil jawaban SA telah memenuhi ketiga indikator yaitu indikator analisis, evaluasi dan solusi yang tepat. Selanjutnya setelah menganalisis hasil tes mahasiswa, kemudian dilakukan wawancara terhadap SA.

Pertanyaan matematika yang telah diberikan kemudian ditanyakan kepada SA melalui wawancara untuk memberikan penguatan akan jawaban soal tes yang sudah dikerjakan. Ketika SA diberikan pertanyaan mengenai pemahaman dalam soal tersebut, jawabannya sudah menjelaskan dengan detail seperti kutipan wawancara berikut:

"Pertanyaan dari soal tersebut yaitu mencari volume bandul, jadi soal itu kita diminta untuk mencari berat bandul. berat bandul diperoleh dari volume bandul dikalikan dengan gram timah"

Jawaban dari pertanyaan wawancara dari SA sudah membuktikan bahwa indikator pertama dapat terpenuhi. Selanjutnya untuk memenuhi indikator kedua yaitu evaluasi diberikan pertanyaan wawancara bagi SA untuk menjelaskan langkah-langkah dalam mengerjakan soal. Jawaban dari wawancara pertanyaan kedua dapat dilihat dari kutipan wawancara berikut:

"Pertama kita cari tahu dulu volume bandul itu terdiri dari bangun ruang apa saja. setelah ketemu kita tinggal menghitung volumenya Volume bandul itu terdiri dari volume kerucut dan volume setengah bola. jadi tinggal menghitung volume kerucut ditambah volume setengah bola kemudian dikalikan dengan berat timah dalam gram".

Dilihat dari jawaban pertanyaan wawancara pada SA menunjukkan bahwa SA mampu mengerjakan langkah-langkah dalam mengerjakan soal. Hal ini membuktikan bahwa SA mampu memnuhi indikator kedua yaitu mengevaluasi soal yang diberikan. Untuk indikator ketiga yaitu memberikan solusi yang tepat juga sudah terjawab dari pertanyaan wawancara. Jadi dapat disimpulkan SA mampu mengerjakan soal HOTS yang diberikan dengan memenuhi ketiga indikator.

Hasil jawaban SB terlihat pada lembar jawab yang disajikan pada Gambar 2.

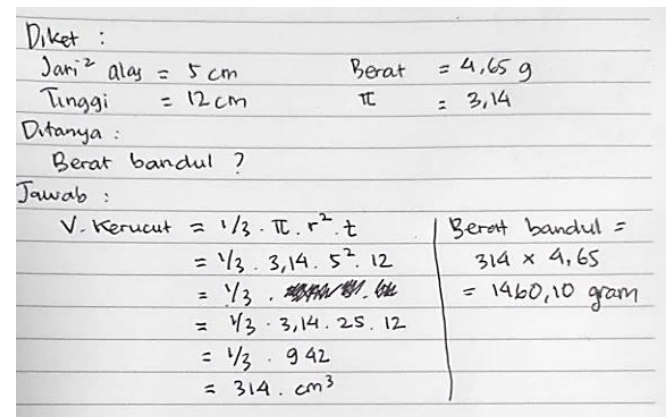

Gambar 2. Jawaban soal pertanyaan dari SB

Dilihat dari hasil jawaban di atas, SB belum mampu menjawab dengan benar sempurna. Jawaban dari SB sudah 
benar sampai pada proses menghitung volume kerucut, tetapi untuk keseluruhan volume bandul belum dihitung. Ini berarti SB hanya mampu menganalisis soal, mengevaluasi tetapi belum mampu memberikan solusi yang tepat. Jadi hasil jawaban untuk SB hanya memenuhi dua indikator yaitu analisis dan evaluasi. Selanjutnya setelah menganalisis hasil tes mahasiswa, kemudian dilakukan wawancara terhadap SB.

Pertanyaan wawancara yang diberikan pada SB sama dengan pertanyaan wawancara terhadap SA. Wawancara ini sebagai penguatan atas hasil tes yang sudah dikerjakan. SB diberikan pertanyaan wawancara mengenai pemahaman terhadap soal tersebut, dapat dilihat pada kutipan wawancara berikut:

"Soalnya diminta untuk menghitung berat bandul. Berat bandul terdiri dari bangun ruang kerucut dan setengah bola. jadi kita harus menghitung dulu volume kerucut dan volume bola".

Dilihat dari jawaban pertanyaan wawancara SB sudah mampu mengetahui langkah dalam mengerjakan soal. Namun perhitungan yang dikerjakan kurang tepat, setelah ditanyakan dalam wawancara SB menjelaskan bahwa ternyata lupa rumus untuk menghitung, dapat dilihat dari kutipan wawancara berikut:

"Iya bu maaf saya lupa rumus volume bola. jadi saya hanya menghitung volume kerucut saja kemudian saya kalikan dengan berat timah"

Jika dilihat dari wawancara dengan SB dapat membuktikan jika belum mampu mngerjakan soal dengan tepat. Hal ini dapat disimpulkan bahwa kemampuan SB dalam mengerjakan soal HOTS yang diberikan masih kurang, karena hanya memenuhi kedua indikator yaitu menganalisis soal dan mengevaluasi soal yang diberikan.

Hasil jawaban SC terlihat pada lembar jawab yang disajikan pada Gambar 3.

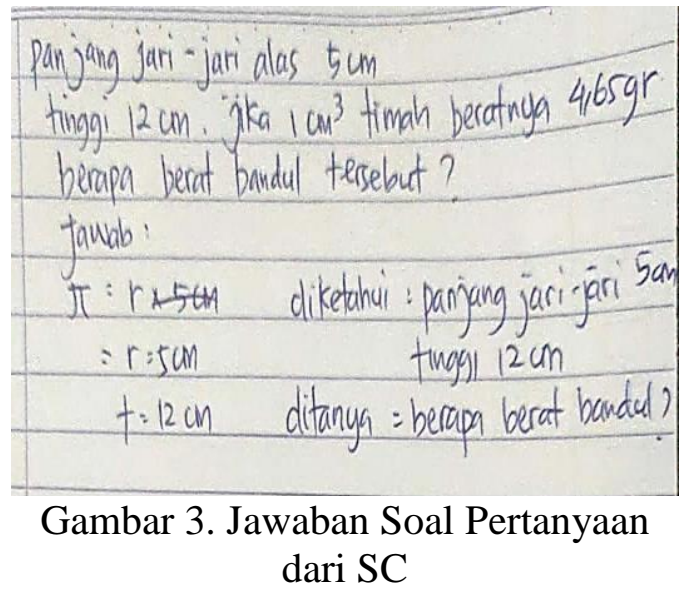

Dilihat dari hasil jawaban pada gambar 3, SC tidak dapat menjawab dengan benar. SC hanya menuliskan kembali petanyaannya saja tanpa menuliskan cara perhitungan. Ini berarti SC sama sekali belum mampu untuk menganalisis soal, mengevaluasi dan memberikan solusi yang tepat. Jadi hasil jawaban untuk SC belum memenuhi ketiga indikator yaitu indikator analisis, evaluasi dan solusi yang tepat. Selanjutnya setelah menganalisis hasil tes mahasiswa, kemudian dilakukan wawancara terhadap SC.

Pertanyaan wawancara yang diberikan pada SC mengenai pemahaman terhadap soal yang diberikan. SC tidak dapat mengerjakan soal karena tidak paham dan lupa rumus.

"Saya kurang paham bu, saya lupa rumus karena saya tidak belajar"

Jawaban wawancara jelas membuktikan bahwa kemampuan SC dalam mengerjakan soal HOTS masih kurang. Jadi kemampuan SC dalam mengerjakan soal HOTS masih rendah. 
DOI: https://doi.org/10.24127/ajpm.v10i2.3522

Berdasarkan dari hasil skor tes mahasiswa ternyata ada banyak mahasiswa pada kelompok kemampuan sedang dan kemampuan rendah. Padahal seharusnya mahasiswa calon guru harus mampu memenuhi kriteria dalam indikator menyelesaikan soal bertipe HOTS. Indikator dalam penelitian ini yaitu menganalisis, mengevaluasi, dan memberikan solusi. Penelitian Widhiyani et al., (2019) menjelaskan bahwa ketiganya harus terpenuhi sebagai kriteria dalam pengerjaan soal HOTS. Pendapat yang sama dari peneliti lain yaitu Rahayuningsih \& Jayanti (2019) menjelaskan bahwa mahasiswa harus memiliki kemampuan untuk dapat mengerjakan soal HOTS sebagai bekal mengajar.

Berdasarkan dari hasil wawancara dengan SA mampu menyelesaikan soal matematika bertipe HOTS. Untuk SB dari hasil wawancara menyatakan bahwa belum mampu menyelesaikan soal matematika bertipe HOTS secara tepat. Jika membandingkan hasil, SB masih kesulitan dalam memberikan solusi dari soal. SB menjelaskan bahwa lupa rumus. Untuk SC diperoleh kesimpulan bahwa tidak mampu menyelesaikan soal matematika bertipe HOTS. Jika dibandikankan dari hasil data sudah terlihat bahwa kemampuan SC masih rendah.

Hasil skor tes dan hasil wawancara sudah terlihat jelas bahwa ternyata kemampuan mahasiswa PGSD dalam mngerjakan soal HOTS masih rendah. Dilihat dari hasil jawaban pada soal tes ketiga subjek, ini membuktikan bahwa kemampuan setiap mahasiswa itu berbeda, tetapi jika terus menerus diasah dengan banyak berlatih mengerjakan soal matematika sehingga kemampuan mahasiswa bertambah. Untuk itu seorang dosen harus mampu mengarahkan mahasiswa agar kemampuan HOTS meningkat dengan memperbanyak soal yang diberikan, Selain itu dosen dapat memberikan triktrik supaya pembelajaran dengan soal HOTS tidak menjemukan mahasiswa. Temuan ini sejalan dengan penelitian Umar \& Ahmad (2019) yang menjelaskan bahwa dosen harus menciptakan kondisi pembelajaran agar terjalin kerjasama dengan mahasiswa.

Penggunaan soal HOTS untuk melihat kemampuan mahasiswa PGSD dalam menyelesaikan soal memberikan dampak positif terhadap mahasiswa dalam pembelajaran Geometri. Mahasiswa yang memiliki kemampuan menyelesaikan soal HOTS diharapkan agar nantinya mahasiswa memiliki bekal yang cukup sebagai calon guru. Seorang guru dalam pembelajaran saat ini harus mempunyai kemampuan dalam mengajarkan soal matematika yang bertipe HOTS di sekolah dasar.

\section{KESIMPULAN DAN SARAN}

Berdasarkan dari hasil dan pembahasan pada penelitian ini dapat disimpulkan bahwa kemampuan mahasiswa PGSD dalam menyelesaikan soal matematika bertipe HOTS masih cukup rendah. Mahasiswa yang termasuk dalam kategori rendah masih perlu bimbingan dosen dalam menyelesaikan soal HOTS.

Saran untuk peneliti selanjutnya yaitu dapat menggali kemampuan mahasiswa untuk menyelesaikan soal HOTS dengan menggunakan matakuliah pembelajaran matematika lain. Penelitian selanjutnya juga dapat melakukan penelitian yang spesifik dengan menggunakan indikator penilaian yang berbeda untuk mengetahui kemampuan mahasiswa dalam pembelajaran mengenai soal HOTS. 


\section{DAFTAR PUSTAKA}

Afrianto. (2018). Being a Professional Teacher in the Era of Industrial Revolution 4 . 0: Opportunities, Challenges and Strategies for Innovative Classroom Practices. English Language Teaching And Research, 2(1), 1-13.

Ahmad, S., Kenedi, A. K., \& Masniladevi, M. (2018). Instrumen Hots Matematika Bagi Mahasiswa Pgsd. Jurnal Pajar (Pendidikan Dan Pengajaran), 2(6), 905. https://doi.org/10.33578/pjr.v2i6.6 530

Amalia, A., Rusdi, \& Kamid. (2021). Pengembangan Soal Matematika Bermuatan HOTS Setara PISA Berkonteks Pancasila. Jurnal Cendekia: Jurnal Pendidikan Matematika, 05(01), 1-19.

Andriyani, R., \& Yenni. (2019). Analisis High Order Thinking Skills (HOTS) Mahasiswa Pada Mata Kuliah Trigonometri. Snp2M, 1(2), 175-179.

Dosinaeng, W. B. N., Leton, S. I., \& Lakapu, M. (2019). Kemampuan Mahasiswa dalam Menyelesaikan Masalah Matematis Berorientasi HOTS. JNPM (Jurnal Nasional Pendidikan Matematika), 3(2), 250-264.

https://doi.org/10.33603/jnpm.v3i 2.2197

Hadi, F. R. (2021). Kesulitan Belajar Siswa Sekolah Dasar Dalam Menyelesaikan Soal Hots Matematika Berdasarkan Teori Newman. Muallimuna: Jurnal Madrasah Ibtidaiyah, 6(2), 4356.

Hadi, W., \& Faradillah, A. (2020). Hambatan Mahasiswa Calon Guru Matematika Dalam Menyelesaikan Masalah
Bermuatan High-Order Thinking Skills. Aksioma: Jurnal Program Studi Pendidikan Matematika, 9(3), 662-670.

Hasyim, M., \& Andreina, F. K. (2019). Analisis High Order Thinking Skill (Hots) Siswa Dalam Menyelesaikan Soal Open Ended Matematika. Fibonacci: Jurnal Pendidikan Matematika Dan Matematika, 5(1), 55. https://doi.org/10.24853/fbc.5.1.5 5-64

Maimunah, Andrari, F. R., \& Qadarsih, N. D. (2020). Analisis Kemampuan Berpikir Calon Guru Dalam Menyelesaikan Permasalahan Matematika Berorientasi Pada Hots. SAP (Susunan Artikel Pendidikan), 5(2), 182-188.

Manik, P., Saraswati, S., Ngurah, G., \& Agustika, S. (2020). Kemampuan Berpikir Tingkat Tinggi Dalam Menyelesaikan Soal HOTS Mata Pelajaran Matematika. Jurnal Ilmiah Sekolah Dasar, 4(2), 257269.

Narayanan, S., \& Adithan, M. (2015). Analysis Of Question Papers In Engineering Courses With Respect To Hots (Higher Order Thinking Skills). American Journal of Engineering Education (AJEE), 6(1), 1-10. https://doi.org/10.19030/ajee.v6i1. 9247

Rahayuningsih, S., \& Jayanti, R. (2019). High Order Thinking Skills (HOTS) Mahasiswa Program Studi Pendidikan Matematika dalam Menyelesaikan Masalah Grup. Majamath: Jurnal Matematika Dan Pendidikan Matematika, 2(2), 87-93. https://doi.org/10.36815/majamat h.v2i2.424 
DOI: https://doi.org/10.24127/ajpm.v10i2.3522

Rosidin, U., Suyatna, A., \& Abdurrahman, A. (2019). A combined HOTS-based assessment/STEM learning model to improve secondary students' thinking skills: A development and evaluation study. Journal for the Education of Gifted Young Scientists, 7(3), 435-448. https://doi.org/10.17478/jegys.518 464

Singh, C. K. S., Singh, R. K. A., Singh, T. S. M., Mostafa, N. A., \& Mohtar, T. M. T. (2018). Developing a Higher Order Thinking Skills Module for Weak ESL Learners. English Language Teaching, 11(7), 86. https://doi.org/10.5539/elt.v11n7p 86

Tambunan, H., \& Naibaho, T. (2019). Performance of mathematics teachers to build students' high order thinking skills (HOTS). Journal of Education and Learning (EduLearn), 13(1), 111. https://doi.org/10.11591/edulearn. v13i1.11218

Tan, S. Y., \& Halili, S. H. (2015). Effective Teaching of HigherOrder Thinking (HOT) in Education. The Online Journal of Distance Education and ELearning, 3(2), 41-47.

Tanujaya, B. (2016). Development of an Instrument to Measure Higher Order Thinking Skills in Senior High School Mathematics Instruction. Journal of Education and Practice, 7(21), 144-148.

Umar, A., \& Ahmad, N. Q. (2019). Analisis Kemampuan Berpikir Kreatif Matematis Calon Guru Matematika. As-Salam, 3(April), 36-47.
Widhiyani, I. A. N. T., Sukajaya, I. N., \& Suweken, G. (2019). Pengembangan Soal Higher Order Thinking Skills Untuk Pengkategorian Kemampuan Pemecahan Masalah Geometri Siswa Smp. Jurnal Pendidikan Dan Pembelajaran Matematika Indonesia, $\quad 8(2), \quad 68-77$. https://doi.org/10.23887/jppm.v8i 2.2854

Winarso, W. (2014). Membangun Kemampuan Berfikir Matematika Tingkat Tinggi Melalui Pendekatan Induktif, Deduktif Dan Induktif-Deduktif Dalam Pembelajaran Matematika. Eduma: Mathematics Education Learning and Teaching, 3(2), 95118.

https://doi.org/10.24235/eduma.v3 i2.58

Yaniawati, R. P. (2013). E-Learning to Improve Higher Order Thinking Skills (HOTS) of Students. Journal of Education and Learning (EduLearn), 7(2), 109. https://doi.org/10.11591/edulearn. v7i2.225

Zulfiani, Suwarna, I. P., \& Sumantri, M. F. (2020). Science adaptive assessment tool: Kolb's learning style profile and student's higher order thinking skill level. Jurnal Pendidikan IPA Indonesia, 9(2), 194-207. https://doi.org/10.15294/jpii.v9i2. 23840 